\title{
Associations Between Submicrometer Particles Exposures and Blood Pressure and Heart Rate in Patients With Lung Function Impairments
}

\author{
Kai-Jen Chuang, MSc \\ Chang-Chuan Chan, ScD \\ Guang-Ming Shiao, MD \\ Ta-Chen Su, MD
}

\section{Learning Objectives}

- State whether the concentration of sub-micrometer particles ranging from 0.02 to $1 \mu \mathrm{m}$ in diameter $\left(\mathrm{NC}_{0.02-1}\right)$ correlated with ambient levels of air pollutants.

- Identify any correlation found in this study of persons with impaired lung function between $\mathrm{NC}_{0.02-1}$ or particles less than $1.0 \mu \mathrm{m}$ in diameter $\left(\mathrm{PM}_{1.0}\right)$ and elevations in systolic and diastolic blood pressure and heart rate.

- Explain the implications of these findings with respect to the risk of cardiovascular disease.

\section{Abstract}

Objective: The objective of this study was to evaluate whether submicrometer particle is associated with elevated blood pressure $(B P)$ and heart rate $(H R)$. Methods: We measured ambulatory systolic BP (SBP), diastolic BP (DBP), and $H R$ using a portable BP monitoring system and number concentrations of submicrometer particle with a size range of 0.02 to $1 \mu \mathrm{m}\left(\mathrm{NC}_{0.02-1}\right)$ by a P-TRAK Ultrafine Particle Counter for 10 patients with lung function impairments. Results: We found $\mathrm{NC}_{0.02-1}$ exposures at 1- to 3-hour moving averages were associated with the elevation of SBP, DBP, and HR. There were 1.4 to 3.4-mm-Hg increases in SBP, 1.4 to 2.2-mm-Hg increases in DBP, and 0.3 to 3.5-beats/min increases in HR for 10,000 particles $/ \mathrm{cm}^{3}$ increases in $\mathrm{NC}_{0.02-1}$ at 1- to 3-hour moving averages. Conclusions: Exposures to submicrometer particles were associated with short-term increases in BP and HR in patients with lung function impairments. (J Occup Environ Med. 2005;47:1093-1098)

From the Institute of Occupational Medicine and Industrial Hygiene, College of Public Health (Mr Chuang, Dr Chan, Dr Su) and Department of Internal Medicine, Cardiology Section, National Taiwan University Hospital (Dr Su), College of Public Health, National Taiwan University, Taipei, Taiwan; and the Chest Department (Dr Shiao), Taipei Veterans General Hospital, Taipei, Taiwan.

This study was supported by a grant from the National Science Council of Taiwan (NSC90-2320B-002-126)

Address correspondence to: Chang-Chuan Chan, ScD, Institute of Occupational Medicine and Industrial Hygiene, College of Public Health, National Taiwan University, Rm. 1447, 1st Sec., No. 1 Ren-ai Rd., Taipei 100, Taiwan; E-mail: ccchan@ha.mc.ntu.edu.tw.

Copyright $(C$ by American College of Occupational and Environmental Medicine

DOI: 10.1097/01.jom.0000181749.03652.f9 pidemiologic studies have shown associations between particulate air pollution and cardiovascular mortality $^{1}$ and morbidity. ${ }^{2}$ Nevertheless, the underlying mechanisms or pathways of particulate matter-induced cardiovascular mortality and morbidity still remain largely unclear. The linkage between decreasing heart rate variability (HRV) and particulate matter less than $10 \mu \mathrm{m}$ in diameter $\left(\mathrm{PM}_{10}\right)$ and less than $2.5 \mu \mathrm{m}$ in diameter $\left(\mathrm{PM}_{2.5}\right)$ has been documented in many panel studies. ${ }^{3-8}$ Several studies have also reported that increased mass concentrations of total suspended particulate matter (TSP), $\mathrm{PM}_{10}$, and $\mathrm{PM}_{2.5}$ were associated with elevating blood pressure $(\mathrm{BP})^{9-11}$ and heart rate $(\mathrm{HR})^{8,12,13}$ in the general population or patients with cardiopulmonary diseases. Comparatively few studies were conducted on the cardiovascular effects by smaller particles such as submicrometer particles with particle size less than $1.0 \mu \mathrm{m}$ in diameter $\left(\mathrm{PM}_{1.0}\right)$ or ultrafine particles with particle size less than $0.1 \mu \mathrm{m}$ in diameter. We recently reported that exposures to submicrometer particles with a size range of 0.02 to $1 \mu \mathrm{m}$ measured by number concentrations $\left(\mathrm{NC}_{0.02-1}\right)$ were associated with lowering HRV in both susceptible and normal populations. ${ }^{14}$ As a follow up of the previous study on patients with lung function impairments, we further investigate whether exposures to submicrometer particles are also associated with changes in their BP and HR in this panel study. 


\section{Materials and Methods}

\section{Study Subjects}

As described in the previous study, ${ }^{14}$ our study panel included 10 patients with lung function impairments who were recruited from the Chest Department of Taipei Veterans General Hospital. The ratios of their forced expiratory volume in 1 second $\left(\mathrm{FEV}_{1.0}\right)$ by forced vital capacity (FVC), $\mathrm{FEV}_{1.0} / \mathrm{FVC}$, were all less than $84 \%$. None of them had hyperthyroidism, hypoxemia, hypercapnia, acute cardiopulmonary failure, or paced cardiac rhythm, or used medication of anticholinergics, beta blockers, or antiarrhythmic agents during the study period. The Institutional Review Board of Taipei Veterans General Hospital approved the research protocol, and written informed consent was obtained from each subject.

\section{Ambulatory Blood Pressure and Heart Rate Monitoring and Recording}

We recorded each subject's BP and HR every 15 minutes during wake time (7:00 AM through 11:00 PM) and every 30 minutes during sleep time (11:00 PM through 7:00 AM) continuously by using a portable BP monitoring system (DynaPulse model 5000A; Pulse Metric, San Diego, CA). The DynaPulse system can measure a subject's arterial pulsation signals, known as the arterial wave form, through a noninvasive cuff device. The systolic blood pressure (SBP), diastolic blood pressure (DBP), and HR readings by DynaPulse have been validated against the traditional mercury sphygmomanometer measurements. ${ }^{15,16}$ Each subject carried a DynaPulse system for 24 hours to complete his continuous BP and HR monitoring. To avoid sleep effects on BP and heart rate, we used the monitor measurements when the subjects were awake between 7:00 AM and 11:00 PM in our data analysis. Each subject obtained approximately 60 successful BP and
HR measurements for further data analysis.

\section{Personal Exposures to Submicrometer Particles}

A detailed description of the sampling procedures and data validation is given in our previous study. ${ }^{14} \mathrm{In}$ brief, $\mathrm{NC}_{0.02-1}$ monitoring was conducted for each subject by a technician carrying a P-TRAK Ultrafine Particle Counter (model 8525; TSI Inc., Shoreview, MN). The raw data of 1-minute $\mathrm{NC}_{0.02-1}$ measurements were first matched with the sampling time of $\mathrm{BP}$ and $\mathrm{HR}$ monitoring and then computed to moving averages if $75 \%$ of the data were present. We obtained approximately 700 measurements of $\mathrm{NC}_{0.02-1}$ moving averages for each subject in our data analysis.

\section{Exposures to Ambient Air Pollution}

In addition to personal $\mathrm{NC}_{0.02-1}$ exposure monitoring, we also included ambient air pollution as our study subjects' exposure data in this study. The concentrations of particulate matters with aerodynamic diameter less than $10 \mu \mathrm{m}\left(\mathrm{PM}_{10}\right)$, nitrogen dioxide $\left(\mathrm{NO}_{2}\right)$, carbon monoxide $(\mathrm{CO})$, sulfur dioxide $\left(\mathrm{SO}_{2}\right)$, and ozone $\left(\mathrm{O}_{3}\right)$ measured at fixed-site air-monitoring stations were used to represent subjects' exposures to ambient air pollution. There were 12 fixed-site air-monitoring stations in Taipei, which were operated by Taiwan Environmental Protection Agency (TEPA). Each of our study subjects can be assigned to one fixed-site monitoring that is within 1 $\mathrm{km}$ of his residence. The hourly data of $\mathrm{PM}_{10}, \mathrm{NO}_{2}, \mathrm{CO}, \mathrm{SO}_{2}$, and $\mathrm{O}_{3}$ in each monitoring station were obtained and matched with the sampling time of BP and HR monitoring to represent our subjects' exposures to ambient air pollutants during the monitoring period. The moving averages were computed and approximately 48 measurements of each air pollutant were obtained for each subject in our data analysis.

\section{Statistical Analysis}

We applied linear mixed-effects regression models to examine the association between air pollutants and BP and HR by using S-PLUS 2000 (MathSoft, Inc.). Our mixedeffects models included BP and HR as outcomes, random effects for subjects, and fixed effects for age, body mass index, tobacco exposure, 1-hour moving averages of temperature, and 1- to 4-hour moving averages of air pollutants including $\mathrm{NC}_{0.02-1}, \mathrm{PM}_{10}, \mathrm{NO}_{2}, \mathrm{CO}, \mathrm{SO}_{2}$, and $\mathrm{O}_{3}$. The 1-hour moving average of temperature was adjusted in our models because it was the only time lag that was associated with HR and $\mathrm{BP}$ among 1- to 4-hour moving averages of temperature tested in this study. To assure that changes in $\mathrm{BP}$ and HR were not the result of diurnal variation of the cardiovascular system, our models also contained hour of day as an indicator variable of fixed effects. We initially conducted single-pollutant models for each of these six air pollutants. We then included the air pollutants, which were significantly associated with BP or HR in single-pollutant models, in our multipollutant models. Outcomes in their original scales were used for further analysis because their distributions were normal as determined by Shapiro-Wilk test. ${ }^{17}$ Autocorrelation within each outcome variable was diagnosed by using autocorrelation residual plots, and no time-dependent autocorrelation was observed in all our models. Model selections were based on the criteria of minimizing Akaike's Information Criterion (AIC). Effects were estimated for changes of $\mathrm{BP}$ and $\mathrm{HR}$ per 10,000 paricles $/ \mathrm{cm}^{3}$ of $\mathrm{NC}_{0.02-1}(\beta$ coefficient $\times 10,000$ ) and per unit of $\mathrm{PM}_{10}, \mathrm{NO}_{2}, \mathrm{CO}, \mathrm{SO}_{2}$, and $\mathrm{O}_{3}(\beta$ coefficient). Our mixed-effects models were further applied separately to analyze the association between $\mathrm{BP}$ and $\mathrm{NC}_{0.02-1}$ for all 10 subjects as a 
whole, two subgroups of $\mathrm{HR} \leqq 72$ beats/min, and HR $>72$ beats/min.

\section{Results}

Subjects' personal characteristics and environmental attributes are summarized in Table 1 . The 10 patients were all male and aged from 42 to 79 , and their body mass indices were from 20.6 to $33.8 \mathrm{~kg} / \mathrm{m}^{2}$. The outcome measurements along with relevant pollution data over the 16hour monitoring period are also shown in Table 1. Our subjects' averages of SBP, DBP, and HR were $133.9 \pm 15.7 \mathrm{~mm} \mathrm{Hg}, 78.0 \pm 11.3$ $\mathrm{mm} \mathrm{Hg}$, and $76.5 \pm 13.4$ beats/min, respectively. The 1-hour averaging $\mathrm{NC}_{0.02-1}$ measurements ranged from 2169 to 93,666 particles $/ \mathrm{cm}^{3}$. The means of 1- to 4-hour averaging $\mathrm{NC}_{0.02-1}$ measurements were $23,785.0 \pm 13,417.0$ particles $/ \mathrm{cm}^{3}$, $24,110.6 \pm 10,947.5$ particles $/ \mathrm{cm}^{3}$, $23,891.4 \pm 11,583.1$ particles/ $\mathrm{cm}^{3}$, and 23,674.9 \pm 11,621.0 particles $/ \mathrm{cm}^{3}$. Air pollution levels averaged at $54.1 \pm 29.5 \mu \mathrm{g} / \mathrm{m}^{3}, 27.6 \pm$ $18.2 \mathrm{ppb}, 1.0 \pm 0.7 \mathrm{ppm}, 22.4 \pm$ $20.0 \mathrm{ppb}$, and $3.5 \pm 4.7 \mathrm{ppb}$ for $\mathrm{PM}_{10}$, $\mathrm{NO}_{2}, \mathrm{CO}, \mathrm{O}_{3}$, and $\mathrm{SO}_{2}$, respectively. Pearson correlation was low among these air pollutants except moderate correlation for $\mathrm{NC}_{0.02-1}$ with $\mathrm{NO}_{2}$ $(\mathrm{r}=0.53)$ and $\mathrm{CO}(\mathrm{r}=0.46)$, and for $\mathrm{NO}_{2}$ with $\mathrm{CO}(\mathrm{r}=0.61)$ and $\mathrm{PM}_{10}$ $(\mathrm{r}=0.57)$.

Table 2 list changes in $\mathrm{BP}$ and $\mathrm{HR}$ for 10,000 paricles $/ \mathrm{cm}^{3} \quad \mathrm{NC}_{0.02-1}$ exposures at 1- to 4-hour moving averages estimated by the singlepollutant models for all 10 subjects and two subgroups. We only examined the time course of $\mathrm{NC}_{0.02-1}$ exposures up to 4-hour moving averages because available data became substantially decreased for moving averages greater than 5

\section{TABLE 1}

Study Participants' Characteristics, Air Pollution Levels, and Meteorologic Variables

\begin{tabular}{|c|c|c|c|c|}
\hline & No. & Mean & Standard Deviation & Range \\
\hline Age, year & 10 & 58.3 & 13.4 & $42-79$ \\
\hline Body mass index, $\mathrm{kg} / \mathrm{m}^{2}$ & 10 & 26.9 & 3.9 & $20.6-33.8$ \\
\hline Systolic blood pressure, mm Hg & 444 & 133.9 & 15.7 & $94.0-180.0$ \\
\hline Diastolic blood pressure, $\mathrm{mm} \mathrm{Hg}$ & 444 & 78.0 & 11.3 & $60.0-115.0$ \\
\hline Heart rate, beats/min & 316 & 76.5 & 13.4 & $44-112$ \\
\hline \multicolumn{5}{|l|}{ Personal exposure } \\
\hline 1-hr moving average $\mathrm{NC}_{0.02-1}$, particles $/ \mathrm{cm}^{3}$ & 6578 & $23,785.0$ & $13,417.0$ & $2169.0-93,666.0$ \\
\hline \multicolumn{5}{|l|}{ Ambient exposure } \\
\hline 1-hr average $\mathrm{PM}_{10}, \mu \mathrm{g} / \mathrm{m}^{3}$ & 470 & 54.1 & 29.5 & $10.3-139.8$ \\
\hline 1-hr average $\mathrm{NO}_{2}$, ppb & 452 & 27.6 & 18.2 & $1.9-123.5$ \\
\hline 1-hr average $\mathrm{CO}, \mathrm{ppm}$ & 472 & 1.0 & 0.7 & $0.1-4.5$ \\
\hline 1-hr average $\mathrm{O}_{3}, \mathrm{ppb}$ & 460 & 22.4 & 20.0 & $0.2-134.1$ \\
\hline 1-hr average $\mathrm{SO}_{2}, \mathrm{ppb}$ & 454 & 3.5 & 4.7 & $0.1-71.0$ \\
\hline \multicolumn{5}{|l|}{ Meteorologic variable } \\
\hline 1 -hr average temperature, ${ }^{\circ} \mathrm{C}$ & 451 & 23.4 & 1.9 & $20.0-27.1$ \\
\hline
\end{tabular}

TABLE 2

Changes* in Blood Pressure and Heart Rate for $\mathrm{NC}_{0.02-1}$ Exposures of 10,000 Particles/cm ${ }^{3}$

\begin{tabular}{|c|c|c|c|c|c|c|c|c|}
\hline & \multicolumn{2}{|c|}{ 1-Hr Moving Average } & \multicolumn{2}{|c|}{ 2-Hr Moving Average } & \multicolumn{2}{|c|}{ 3-Hr Moving Average } & \multicolumn{2}{|c|}{ 4-Hr Moving Average } \\
\hline & Changes & $95 \% \mathrm{Cl}$ & Changes & $95 \% \mathrm{Cl}$ & Changes & $95 \% \mathrm{Cl}$ & Changes & $95 \% \mathrm{Cl}$ \\
\hline \multicolumn{9}{|l|}{ Systolic blood pressure, $\mathrm{mm} \mathrm{Hg}$} \\
\hline All subjects & 1.40 & $0.05-2.76$ & 3.40 & $1.16-5.67$ & 2.60 & $-0.10-5.34$ & -1.10 & $-3.07-0.95$ \\
\hline $\begin{array}{l}\text { Subjects with heart rate }>72 \\
\text { beats } / \mathrm{min}\end{array}$ & 1.00 & $-0.96-2.96$ & 4.00 & $0.67-7.33$ & 1.89 & $-2.33-6.12$ & 1.00 & $-3.72-3.72$ \\
\hline $\begin{array}{l}\text { Subjects with heart rate } \leqq 72 \\
\text { beats } / \mathrm{min}\end{array}$ & 0.60 & $-1.16-2.36$ & 1.00 & $-2.00-4.03$ & 1.59 & $-2.03-5.21$ & -1.73 & $-3.76-0.30$ \\
\hline All subjects & 1.40 & $0.46-2.25$ & 2.20 & $0.81-3.68$ & 1.90 & $0.10-3.62$ & -0.70 & $-2.03-0.67$ \\
\hline $\begin{array}{l}\text { Subjects with heart rate }>72 \\
\text { beats } / \mathrm{min}\end{array}$ & 1.76 & $0.42-3.10$ & 3.22 & $1.13-5.32$ & 2.35 & $-0.42-5.13$ & 1.80 & $-0.71-4.30$ \\
\hline $\begin{array}{l}\text { Subjects with heart rate } \leqq 72 \\
\text { beats } / \mathrm{min}\end{array}$ & 0.62 & $-0.67-1.91$ & 0.57 & $-1.58-2.72$ & 0.96 & $-1.38-3.29$ & -2.52 & $-5.01-0.03$ \\
\hline Heart rate, beats/min & 0.28 & $0.34-2.22$ & 1.22 & $0.43-4.02$ & 3.50 & $1,51-5.57$ & 0.50 & $-1.03-1.98$ \\
\hline
\end{tabular}

*Model was adjusted for age, body mass index, tobacco exposure, hour of day, and 1-hr moving average of temperature.

$\mathrm{Cl}$ indicates confidence interval. 
hours. Our single-pollutant models showed that $\mathrm{NC}_{0.02-1}$ was significantly associated with SBP and DBP and HR. $\mathrm{NC}_{0.02-1}$ exposures at 1- to 3-hour moving averages significantly increased all subjects' SBP, DBP, and HR. For 10,000 particles/ $\mathrm{cm}^{3} \mathrm{NC}_{0.02-1}$ exposures, the singlepollutant models showed 1.4 to 3.4-mm-Hg increase in SBP, 1.4 to $2.2-\mathrm{mm}-\mathrm{Hg}$ increase in DBP, and a 0.3 to 3.5 -beats $/ \mathrm{min}$ increase in HR, respectively. For the patients with HR $>72$ beats/min, we found their SBP change was significantly associated with $\mathrm{NC}_{0.02-1}$ exposures at 2-hour moving average and $\mathrm{DBP}$ change was associated with $\mathrm{NC}_{0.02-1}$ exposures at 1- to 2-hour moving averages. By contrast, no association was found between $\mathrm{BP}$ and $\mathrm{NC}_{0.02-1}$ in subjects with $\mathrm{HR} \leqq 72$ beats/min.
The modeling results of the other five ambient air pollutants by our single-pollutant models are list in Table 3. We found a significantly positive association between $\mathrm{CO}$ exposure and HR among our study subjects. For $1 \mathrm{ppm} \mathrm{CO}$ exposures at 1-hour and 2-hour moving averages, we found 3.7 beats/min and 3.9 beats/min increases in HR, respectively. The observed trends between $\mathrm{PM}_{10}$ and $\mathrm{NO}_{2}$ and $\mathrm{HR}$, although positive, were not statistically significant. Our single-pollutant models showed no association between BP with $\mathrm{PM}_{10}, \mathrm{NO}_{2}, \mathrm{CO}, \mathrm{SO}_{2}$, or $\mathrm{O}_{3}$.

Multipollutant models with $\mathrm{NC}_{0.02-1}$ and $\mathrm{CO}$ were performed to estimate the partial effects of $\mathrm{NC}_{0.02-1}$ on $\mathrm{HR}$ with $\mathrm{CO}$ exposures and other key personal and environmental attributes being adjusted. We found only $\mathrm{NC}_{0.02-1}$ remained positively associated with HR in the multipollutant models. As shown in Figure 1, our subjects' heart rates were increased by approximately 0.6 beats/ min and 3.9 beats/min for every

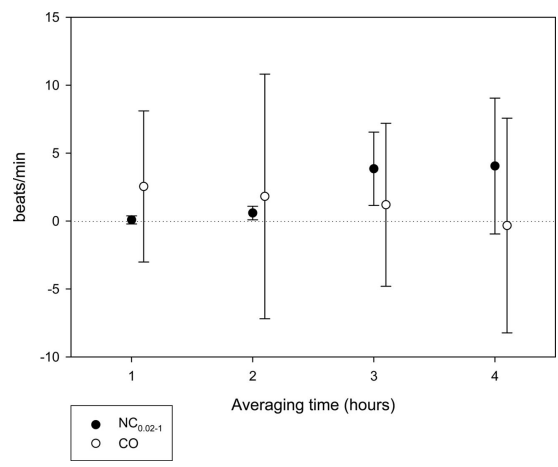

Fig. 1. Changes in heart rate per 10,000 particles $/ \mathrm{cm}^{3} \mathrm{NC}_{0.02-1}$ and $1 \mathrm{ppm} \mathrm{CO}$ estimated by multipollutant mixed-effects models.

\section{TABLE 3}

Changes* in Blood Pressure and Heart Rate for Ambient Air Pollutant Exposures

\begin{tabular}{|c|c|c|c|c|c|c|c|c|c|c|}
\hline & \multicolumn{2}{|c|}{$\begin{array}{c}\mathrm{PM}_{10} \\
\left(1 \mu \mathrm{g} / \mathrm{m}^{3}\right)\end{array}$} & \multicolumn{2}{|c|}{$\begin{array}{l}\text { Nitrogen Dioxide } \\
\text { (1 ppb) }\end{array}$} & \multicolumn{2}{|c|}{$\begin{array}{c}\text { Carbon Monoxide } \\
\text { (1 ppm) }\end{array}$} & \multicolumn{2}{|c|}{$\begin{array}{l}\text { Sulfur Dioxide } \\
\text { (1 ppb) }\end{array}$} & \multicolumn{2}{|c|}{$\begin{array}{l}\text { Ozone } \\
\text { (1 ppb) }\end{array}$} \\
\hline & Changes & $95 \% \mathrm{Cl}$ & Changes & $95 \% \mathrm{Cl}$ & Changes & $95 \% \mathrm{Cl}$ & Changes & $95 \% \mathrm{Cl}$ & Changes & $95 \% \mathrm{Cl}$ \\
\hline \multicolumn{11}{|l|}{$\begin{array}{c}\text { Systolic blood } \\
\text { pressure }\end{array}$} \\
\hline $\begin{array}{c}\text { 1-hr moving } \\
\text { average }\end{array}$ & -0.12 & $-0.24-0.00$ & -0.10 & $-0.31-0.11$ & 0.04 & $-4.54-4.62$ & -0.29 & $-1.25-0.66$ & -0.07 & $-0.24-0.11$ \\
\hline $\begin{array}{l}\text { 2-hr moving } \\
\text { average }\end{array}$ & -0.17 & $-0.34-0.00$ & -0.11 & $-0.33-0.10$ & -0.49 & $-5.33-4.36$ & -0.38 & $-1.03-0.26$ & -0.07 & $-0.25-0.11$ \\
\hline $\begin{array}{l}\text { 3-hr moving } \\
\text { average }\end{array}$ & -0.20 & $-0.40-0.01$ & -0.09 & $-0.32-0.13$ & -0.31 & $-5.65-5.02$ & -0.34 & $-1.07-0.39$ & -0.10 & $-0.28-0.08$ \\
\hline $\begin{array}{l}\text { 4-hr moving } \\
\text { average }\end{array}$ & -0.18 & $-0.37-0.01$ & -0.10 & $-0.34-0.15$ & -0.58 & $-6.48-5.32$ & -0.47 & $-1.31-0.37$ & -0.13 & $-0.31-0.06$ \\
\hline \multicolumn{11}{|l|}{$\begin{array}{l}\text { Diastolic blood } \\
\text { pressure }\end{array}$} \\
\hline $\begin{array}{l}\text { 1-hr moving } \\
\text { average }\end{array}$ & -0.07 & $-0.16-0.01$ & -0.07 & $-0.21-0.08$ & 0.61 & $-2.53-3.76$ & -0.51 & $-1.15-0.14$ & -0.08 & $-0.19-0.04$ \\
\hline $\begin{array}{l}\text { 2-hr moving } \\
\text { average }\end{array}$ & -0.10 & $-0.20-0.00$ & -0.06 & $-0.20-0.09$ & 0.67 & $-2.66-3.99$ & -0.11 & $-0.56-0.33$ & -0.07 & $-0.19-0.06$ \\
\hline $\begin{array}{l}\text { 3-hr moving } \\
\text { average }\end{array}$ & -0.13 & $-0.27-0.01$ & -0.07 & $-0.23-0.09$ & 0.72 & $-2.95-4.38$ & -0.26 & $-0.76-0.24$ & -0.09 & $-0.21-0.03$ \\
\hline $\begin{array}{c}\text { 4-hr moving } \\
\text { average }\end{array}$ & -0.14 & $-0.28-0.00$ & -0.08 & $-0.25-0.09$ & 0.20 & $-3.91-4.30$ & -0.38 & $-1.00-0.20$ & -0.09 & $-0.22-0.03$ \\
\hline \multicolumn{11}{|l|}{ Heart rate } \\
\hline $\begin{array}{c}\text { 1-hr moving } \\
\text { average }\end{array}$ & 0.02 & $-0.08-0.12$ & 0.04 & $-0.12-0.20$ & 3.71 & $0.10-7.32$ & -0.19 & $-0.93-0.55$ & -0.01 & $-0.13-0.10$ \\
\hline $\begin{array}{l}\text { 2-hr moving } \\
\text { average }\end{array}$ & 0.01 & $-0.10-0.13$ & 0.02 & $-0.14-0.19$ & 3.93 & $0.65-7.21$ & -0.31 & $-1.14-0.52$ & -0.02 & $-0.13-0.10$ \\
\hline $\begin{array}{c}\text { 3-hr moving } \\
\text { average }\end{array}$ & 0.03 & $-0.09-0.16$ & -0.00 & $-0.17-0.17$ & 3.40 & $-1.02-7.82$ & 0.00 & $-0.61-0.61$ & -0.03 & $-0.14-0.09$ \\
\hline $\begin{array}{l}\text { 4-hr moving } \\
\text { average }\end{array}$ & 0.03 & $-0.11-0.17$ & 0.00 & $-0.19-0.19$ & 3.63 & $-1.64-8.91$ & 0.25 & $-0.44-0.93$ & -0.05 & $-0.17-0.07$ \\
\hline
\end{tabular}


10,000 particles $/ \mathrm{cm}^{3}$ increase in 2-hour and 3-hour $\mathrm{NC}_{0.02-1}$ moving averages, respectively. We also intentionally forced performed $\mathrm{PM}_{10}$ to our multipollutant models with $\mathrm{NC}_{0.02-1}$ to see whether it could modify $\mathrm{NC}_{0.02-1}$ effects on $\mathrm{BP}$ and HR. We found the partial effects of $\mathrm{NC}_{0.02-1}$ on $\mathrm{BP}$ and $\mathrm{HR}$ remained the same as those in the models without $\mathrm{PM}_{10}$. By contrast, we found $\mathrm{PM}_{10}$ was not associated with $\mathrm{BP}$ and $\mathrm{HR}$ changes in the models (data not shown).

\section{Discussion}

The effects of $\mathrm{NC}_{0.02-1}$ on elevating SBP and DBP among our subjects, who were patients with lung function impairments, were similar to the effects of $\mathrm{PM}_{2.5}$ on cardiac rehabilitation patients reported by Zanobetti et al. ${ }^{11}$ By contrast, the association among $\mathrm{PM}_{10}, \mathrm{SBP}$, and DBP increase was either relatively small among subjects with severe chronic obstructive pulmonary disease (COPD) in a Los Angeles ${ }^{10}$ or not significant among healthy adults in a São Paulo, Brazil, study. ${ }^{18}$ There was also a slight association between TSP and SBP increase among a general population aged 25 to 64 years in an Augsburg study, Germany. ${ }^{9}$ These studies demonstrated that smaller $\mathrm{PM}$, ie, $\mathrm{PM}_{1.0}$ and $\mathrm{PM}_{2.5}$, could have greater effects on BP than larger $\mathrm{PM}, \mathrm{ie}, \mathrm{PM}_{10}$ and TSP. Another interesting finding of our study is that greater $\mathrm{NC}_{0.02-1}$ effects on $\mathrm{BP}$ were observed for subjects with higher heart rates (HR $>72$ beats/ min) compared with those with lower heart rates (HR $\leqq 72$ beats/ min). One previous study also reported similar results, which showed $\mathrm{PM}_{2.5}$ had greater effects on DBP for cardiac rehabilitation patients with higher heart rates (HR $\geq 70$ beats/ min) compared with those with lower heart rates (HR $<70$ beats/ min). ${ }^{11}$ Such findings imply that HR seems to work as a modifier in the particulate effects on blood pressure.

The effects of $\mathrm{NC}_{0.02-1}$ on $\mathrm{HR}$ increase in our subjects were consis- tent with previous findings of $\mathrm{PM}_{10}$ on HR increase in cardiopulmonary patients in Utah Valley and Rome, Italy. ${ }^{12,13}$ Although CO was associated with elevated HR in singlepollutant models, we found no such association in the multipollutant models with both $\mathrm{CO}$ and $\mathrm{NC}_{0.02-1}$. We think that $\mathrm{CO}$ may serve as a surrogate pollutant of submicrometer particles, which have not yet been routinely monitored in most airmonitoring stations. We believe our data generally support that changes in submicrometer particles rather than $\mathrm{CO}$ can lead to increases in HR among patients with lung function impairments.

Evidence has shown that activation of the sympathetic nervous system plays an important role in hypertension and alteration of $\mathrm{BP}$ and HR. ${ }^{19,20}$ The findings of $\mathrm{NC}_{0.02-1}$ exposures on $\mathrm{BP}$ and $\mathrm{HR}$ in this study and on HRV in our previous study ${ }^{14}$ suggest that $\mathrm{NC}_{0.02-1}$ can have both immediate and cumulative effects on cardiac autonomic function in patients with lung function impairments. In vivo studies have shown that particles can affect both sympathetic and parasympathetic nervous systems directly in the immediate phase after exposures. ${ }^{21,22}$ Studies also showed that inhaled particles less than $100 \mathrm{~nm}$ could rapidly pass into the blood circulation of human subjects and experimental hamsters in a few minutes and peak around 20 to 30 minutes after exposure. ${ }^{23,24}$ Such a direct effect of PM represents a plausible explanation for the occurrence of rapid cardiovascular responses to 1-hour moving average of $\mathrm{NC}_{0.02-1}$ exposures. Studies also showed that vascular endothelial perturbation $^{25}$ and systemic inflammation $^{26-28}$ and then altered sympathetic nerve activity and blood pressure $^{29}$ would occur hours and days after PM exposures in either human subjects or experimental animals. Accordingly, we believe particles-induced systemic inflammation can also indirectly result in BP and HR changes in the delayed phase after $\mathrm{NC}_{0.02-1}$ exposures. This may explain why $\mathrm{BP}$ and $\mathrm{HR}$ increase reaches its peak at 2 to 3 hours after $\mathrm{NC}_{0.02-1}$ exposure in this study.

Our findings of the association between $\mathrm{NC}_{0.02-1}$ and increase in $\mathrm{BP}$ and HR can be confounded by unavailable personal exposure data of other air pollutants in this study. The lack of personal exposure to $\mathrm{NO}_{2}$, $\mathrm{O}_{3}$, and $\mathrm{SO}_{2}$ may still confound the observed associations between $\mathrm{NC}_{0.02-1}$ and increase in $\mathrm{BP}$ and $\mathrm{HR}$ even though no such association has been found by using fixed-site monitoring data. Because these unmeasured air pollutants are usually correlated with PM, we may bias study outcomes toward either positive or null results. ${ }^{30,31}$ Comorbidity and medication in our patients with lung function impairments can still confound our findings, although we have used very strict criteria to exclude cases with severe chronic diseases and specific medication from our study subjects. Larger sample size is still needed to extrapolate our findings because the effects of timeinvariant variables such as age and body mass index on between-subjects BP and HR may not be completely evaluated by our relatively small sample size $(n=10)$. However, we had sufficient sample size ( $n=444$ of BP and 316 of HR) to evaluate the effects of time-varying environmental factors on withinsubject changes in $\mathrm{BP}$ and $\mathrm{HR}$.

Regardless of these limitations, we believe our data generally support that changes in $\mathrm{NC}_{0.02-1}$ can lead to increases in BP and HR among patients with lung function impairments. Both elevated BP and HR can serve as markers for altered autonomic activity. ${ }^{19,32}$ Cardiovascular mortality and morbidity are also reported to be increased by elevated $\mathrm{BP}^{33,34}$ or higher HR. ${ }^{35,36}$ However, it is still unknown whether shortterm and small fluctuations of autonomic activity are associated with higher risks of cardiovascular diseases clinically. Therefore, further studies on environmental cardiology 
are needed to determine whether the $\mathrm{NC}_{0.02-1}$-associated autonomic activity fluctuations observed in this panel study will have meaningful implications on cardiovascular mortality clinically.

\section{References}

1. Pope CA 3rd, Burnett RT, Thurston GD, et al. Cardiovascular mortality and longterm exposure to particulate air pollution: epidemiological evidence of general pathophysiological pathways of disease. Circulation. 2004;109:71-77.

2. Morris RD. Airborne particulates and hospital admissions for cardiovascular disease: a quantitative review of the evidence. Environ Health Perspect. 2001; 109(suppl 4):495-500.

3. Creason J, Neas L, Walsh D, et al. Particulate matter and heart rate variability among elderly retirees: the Baltimore 1998 PM study. J Expo Anal Environ Epidemiol. 2001;11:116-122.

4. Gold DR, Litonjua A, Schwartz J, et al. Ambient pollution and heart rate variability. Circulation. 2000;101:1267-1273.

5. Holguin F, Tellez-Rojo MM, Hernandez $\mathrm{M}$, et al. Air pollution and heart rate variability among the elderly in Mexico City. Epidemiology. 2003;14:521-527.

6. Liao D, Creason J, Shy C, et al. Daily variation of particulate air pollution and poor cardiac autonomic control in the elderly. Environ Health Perspect. 1999; 107:521-525.

7. Magari SR, Hauser R, Schwartz J, et al. Association of heart rate variability with occupational and environmental exposure to particulate air pollution. Circulation. 2001;104:986-991.

8. Pope CA 3rd, Verrier RL, Lovett EG, et al. Heart rate variability associated with particulate air pollution. Am Heart J. 1999;138:890-899.

9. Ibald-Mulli A, Stieber J, Wichmann HE, et al. Effects of air pollution on blood pressure: a population-based approach. Am J Public Health. 2001;91:571-577.

10. Linn WS, Gong H Jr, Clark KW, et al. Day-to-day particulate exposures and health changes in Los Angeles area residents with severe lung disease. J Air Waste Manag Assoc. 1999;49:108-115.

11. Zanobetti A, Canner MJ, Stone PH, et al. Ambient pollution and blood pressure in cardiac rehabilitation patients. Circulation. 2004;110:2184-2189.
12. Lagorio S, Forastiere F, Pistelli R, et al. Air pollution and cardiac and respiratory function in a panel of patients. Ann Ist Super Sanita. 2003;39:395-404.

13. Peters A, Perz S, Doring A, et al. Increases in heart rate during an air pollution episode. Am J Epidemiol. 1999;150: 1094-1098.

14. Chan CC, Chuang KJ, Shiao GM, et al. Personal exposure to submicrometer particles and heart rate variability in human subjects. Environ Health Perspect. 2004; 112:1063-1067.

15. Brinton TJ, Walls ED, Chio SS. Validation of pulse dynamic blood pressure measurement by auscultation. Blood Press Monit. 1998;3:121-124.

16. Brinton TJ, Walls ED, Yajnik AK, et al. Age-based differences between mercury sphygmomanometer and pulse dynamic blood pressure measurements. Blood Press Monit. 1998;3:125-129.

17. Shapiro SS, Wilk MB. An analysis of variance test for normality (complete samples). Biometrika. 1965;52:591-611.

18. de Paula Santos U, Braga AL, Giorgi $\mathrm{DM}$, et al. Effects of air pollution on blood pressure and heart rate variability: a panel study of vehicular traffic controllers in the city of Sao Paulo, Brazil. Eur Heart J. 2005;26:193-200.

19. Grassi G. Role of the sympathetic nervous system in human hypertension. J Hypertens. 1998;16:1979-1987.

20. Malpas SC. The rhythmicity of sympathetic nerve activity. Prog Neurobiol. 1998;56:65-96.

21. Kodavanti UP, Schladweiler MC, Ledbetter $\mathrm{AD}$, et al. The spontaneously hypertensive rat as a model of human cardiovascular disease: evidence of exacerbated cardiopulmonary injury and oxidative stress from inhaled emission particulate matter. Toxicol Appl Pharmacol. 2000;164:250-263.

22. Lai CJ, Kou YR. Stimulation of vagal pulmonary c-fibers by inhaled wood smoke in rats. J Appl Physiol. 1998;84: 30-36.

23. Nemmar A, Vanbilloen H, Hoylaerts MF, et al. Passage of intratracheally instilled ultrafine particles from the lung into the systemic circulation in hamster. Am J Respir Crit Care Med. 2001;164:16651668.

24. Nemmar A, Hoet PH, Vanquickenborne $\mathrm{B}$, et al. Passage of inhaled particles into the blood circulation in humans. Circulation. 2002;105:411-414.

25. Bouthillier L, Vincent R, Goegan P, et al. Acute effects of inhaled urban particles and ozone: lung morphology, macrophage activity, and plasma endothelin-1. Am J Pathol. 1998;153:1873-1884.

26. Peters A, Doring A, Wichmann HE, et al. Increased plasma viscosity during an air pollution episode: a link to mortality? Lancet. 1997;349:1582-1587.

27. Peters A, Frohlich M, Doring A, et al. Particulate air pollution is associated with an acute phase response in men; results from the MONICA-Augsburg Study. Eur Heart J. 2001;22:1198-1204.

28. Schwartz J. Air pollution and blood markers of cardiovascular risk. Environ Health Perspect. 2001;109(suppl 3):405409.

29. Nakamura K, Sasaki S, Moriguchi J, et al. Central effects of endothelin and its antagonists on sympathetic and cardiovascular regulation in SHR-SP. J Cardiovasc Pharmacol. 1999;33:876-882.

30. Zeger SL, Thomas D, Dominici F, et al. Exposure measurement error in timeseries studies of air pollution: concepts and consequences. Environ Health Perspect. 2000;108:419-426.

31. Zeka A, Schwartz J. Estimating the independent effects of multiple pollutants in the presence of measurement error: an application of a measurement-errorresistant technique. Environ Health Perspect. 2004;112:1686-1690.

32. Bootsma M, Swenne CA, Van Bolhuis $\mathrm{HH}$, et al. Heart rate and heart rate variability as indexes of sympathovagal balance. Am J Physiol. 1994;66:H15651571.

33. Psaty BM, Furberg CD, Kuller LH, et al. Association between blood pressure level and the risk of myocardial infarction, stroke, and total mortality: the cardiovascular health study. Arch Intern Med. 2001;161:1183-1192.

34. Sesso HD, Stampfer MJ, Rosner B, et al. Systolic and diastolic blood pressure, pulse pressure, and mean arterial pressure as predictors of cardiovascular disease risk in men. Hypertension. 2000;36:801807.

35. Greenland P, Daviglus ML, Dyer AR, et al. Resting heart rate is a risk factor for cardiovascular and noncardiovascular mortality: the Chicago Heart Association Detection Project in Industry. Am J Epidemiol. 1999;149:853-862.

36. Kannel WB, Kannel C, Paffenbarger RS $\mathrm{Jr}$, et al. Heart rate and cardiovascular mortality: the Framingham Study. Am Heart J. 1987;113:1489-1494. 